\title{
BRCA1 mRNA expression modifies the effect of $T$ cell activation score on patient survival in breast cancer
}

\author{
Lingeng $\mathrm{Lu}^{1^{*}} \mathbb{D}$, Huatian Huang ${ }^{2}$, Jing Zhou ${ }^{3}$, Wenxue $\mathrm{Ma}^{4}$, Sean Mackay ${ }^{3}$ and Zuoheng Wang ${ }^{5 *}$
}

\begin{abstract}
Background: Effector $C D 8^{+} \mathrm{T}$ cell activation and its cytotoxic function to eradicate tumor cells depend on the $T$ cell recognition of tumor neoantigens, and are positively associated with improved survival in breast cancer. Tumor suppressor BRCA1 and cell cycle regulator CCND1 play a critical role in maintaining genome integrity and tumorigenesis, respectively. However, it is still unclear how BRCA1 and CCND1 expression levels affect the effect of $\mathrm{T}$ cell activation on breast cancer patient survival.
\end{abstract}

Methods: The interactions between T cell activation status and either BRCA1 or CCND1 expression were evaluated using Kaplan-Meier survival curves and multivariate Cox regression models in a public dataset with 1088 breast cancer patients.

Results: Among the patients with low BRCA1 or CCND1 expression, the Activation group showed better overall survival than the Exhaustion group. Adjusted hazards ratios were 0.43 (95\% Cl: $0.20-0.93$ ) in patients with a low BRCA1 level, and 0.39 (95\% Cl: 0.19-0.81) in patients with a low CCND1 level, respectively. There was a significant trend in both subgroups ( $p$-trend $=0.011$ in the low BRCA1 group, and $p$-trend $=0.009$ in the low CCND1 group). In contrast, there is no significant association in patients with either high BRCA1 or high CCND1 levels. There is a significant interaction between T cell activation status and BRCA1 level $(p=0.009)$, but not between $T$ cell activation status and CCND1 level $(p=0.135)$.

Conclusions: BRCA1 expression modified the effect of T cell activation status on patient survival in breast cancer, suggesting that the existence of neoantigens and the enhancement of neoantigen presentation in combination with immune checkpoint blockade may have synergistic effects on patient outcome.

Keywords: Breast cancer, BRCA1, CCND1, Prognosis, T cell activation score

\section{Background}

Three key components, tumor infiltrating lymphocytes (TILs), neoantigens, and effector $\mathrm{CD} 8^{+} \mathrm{T}$ cell activation, are involved in the development and progression of human cancers including breast cancer. TILs are a mixture of different types of mononuclear immune cells, mainly dominated by $\mathrm{T}$ cells $[1,2]$. Infiltrated $\mathrm{T}$ cells are

\footnotetext{
* Correspondence: Lingeng.lu@yale.edu; zuoheng.wang@yale.edu 'Department of Chronic Disease Epidemiology, Yale School of Public Health, School of Medicine, Center for Biomedical Data Science, Yale Cancer Center, Yale University, 60 College Street, New Haven, CT 06520-8034, USA ${ }^{5}$ Department of Biostatistics, Yale School of Public Health, School of Medicine, Center for Biomedical Data Science, Yale Cancer Center, Yale University, 60 College Street, New Haven, CT 06520-8034, USA

Full list of author information is available at the end of the article
}

primed and activated by tumor neoantigens to be effector T cells, which execute their cytotoxic activities to eliminate tumor cells. Neoantigens are neo-epitopes solely raised in tumor cells, and are generated by tumor-specific DNA alterations that lead to the change of protein sequences. These alterations are one of the key features triggering antitumor immunity. Based on whole-exome sequencing data from 19 types of human cancer, Turajlic et al. [3] found insertion/deletion and non-synonymous mutations in pan-cancer patients. They also demonstrated that the presence of mutationspecific neoantigens was positively associated with $\mathrm{T}$ cell activation and checkpoint inhibitor response [3]. Neoantigens bind to MHC class I molecules and are

(C) The Author(s). 2019 Open Access This article is distributed under the terms of the Creative Commons Attribution 4.0 International License (http://creativecommons.org/licenses/by/4.0/), which permits unrestricted use, distribution, and 
recognized by $\mathrm{CD}^{+} \mathrm{T}$ cells. Thus, the efficacy of checkpoint immunotherapy, adoptively transferred $\mathrm{T}$ cells and engineered chimeric antigen receptor $\mathrm{T}$ (CAR-T) cells depends on the presence of neoantigens on tumor cells [4-8]. However, during the co-evolution of tumor and stromal cells, immunosuppressive microenvironments are fostered, and effector $\mathrm{CD}^{+} \mathrm{T}$ cells are exhausted, resulting in the escape of tumor cells from the immune surveillance.

A battery of inhibitory molecules are associated with effector $\mathrm{CD}^{+} \mathrm{T}$ cell exhaustion [9]. Cytotoxic T lymphocyte antigen 4 (CTLA4) and programmed cell death-1 receptor (PD-1) are two extensively investigated inhibitors that dampen the function of effector $\mathrm{T}$ cells by engaging as receptors of their ligands [10]. Immune checkpoint-based immunotherapies benefit patient's outcomes by reinvigorating effector $\mathrm{CD}^{+} \mathrm{T}$ cells to destroy tumor cells. Anti-CTLA4 (ipilimumab, tremelimumab) and anti-PD-1 (nivolumab, pembrolizumab) immunotherapies have been approved by the United States Food and Drug Administration (FDA) for different types of human cancer. An objective response rate of $18.5 \%$ was observed in a phase I trial of anti-PD-1 antibodies in PD-L1-positive triple-negative breast cancer patients [11], which indicates that a substantial proportion of patients in trials did not respond well to the checkpoint immunotherapies. Two possibilities, if not all but at least, may explain the failure to respond to the checkpoint immunotherapies. One is that other inhibitory molecules beyond CTLA4 and PD-1, for example, TIM3, LAG3 and TIGIT, are directly or indirectly, but synergistically involved in the exhaustion of effector $\mathrm{T}$ cells [12, 13]. Another possibility is the insufficient amount of neoantigens on tumor cells. Recently, FDA approved the first monoclonal antibody of pembrolizumab (Keytruda) for solid human cancer with DAN repair deficiency. Patients with DNA repair deficiency show significant improvement in both the objective response rate and the survival rate when compared to those with DNA repair proficiency [14-16]. Several case reports show that patients who have better response to immune checkpoint blockade carry higher levels of MHC class I molecule in microsatellite unstable tumors [17-19]. These findings warrant further studies to investigate how neoantigen loads in tumors affect patients' response to immunotherapies.

BRCA1 is a tumor suppressor with DNA repair function through homologous recombination in response to DNA double-stranded breaks. BRCA1 deficiency results in genomic instability and individual's susceptibility to breast and ovarian cancer [20-22]. Recently, Green and colleagues reported that low $B R C A 1$ expression was associated with high numbers of $\mathrm{CD}^{+}$TILs and poor survival in patients with breast cancer [23].

The process and presentation of peptide antigens in antigen-presenting cells include peptide cleavage, peptide transportation to membrane and its interaction with major histocompatibility complex (MHC) class I molecules. Recently, Goel and colleagues [24] reported that cyclin-dependent kinases CDK4/6 inhibitors triggered anti-tumor immunity by upregulating the expression of genes involved in the process and presentation of peptide antigens. Cyclin D1 (CCND1) is a regulatory cofactor of CDK4/6, and is overexpressed in breast cancer [25]. It has been shown that CCND1 and MHC-I molecules are negatively correlated in breast cancer [24], suggesting CCND1 may modulate the presentation of peptide antigens, thereby affecting $\mathrm{T}$ cell activation.

We recently reported that high $\mathrm{T}$ cell activation score was positively associated with better survival in breast cancer patients [26]. Given that impaired DNA repair such as deficiency in BRCA1 results in genomic instability and susceptibility to genotoxic stress, and consequently leads to the increase of somatic mutations and neoantigens, we sought to answer the question whether the expression of BRCA1 and CCND1 modifies the effect of $\mathrm{T}$ cell activation on patients' survival in breast cancer.

\section{Methods \\ Study subjects}

In this study, 1088 female patients with primary breast cancer, whose clinical data were retrieved from a TCGA dataset, were included. The average age at diagnosis was 58.3 (range: $26-90$ ) years old. $75.7 \%$ (752 of 994) patients were Caucasians. Among the 1088 patients, 64.8\% were post-menopause women, $21.1 \%$ pre-menopause, $3.7 \%$ peri-menopause, $3.1 \%$ indeterminate, and $7.3 \%$ unknown. Ductal carcinoma accounted for $71.8 \%(n=780)$, followed by $18.6 \%$ lobular $(n=202), 4.9 \%$ mix $(n=53)$, and $4.7 \%$ other $(n=51)$. Majority of patients were diagnosed with breast cancer at early stage (181 (16.8\%) stage I, and $616(57.2 \%)$ stage II), and $26.0 \%(n=280)$ at advanced stage (III or IV). Among the 1038 women with a known estrogen receptor (ER) status, $77.1 \%$ were ER-positive. Among the 719 patients with a known HER2 status, 22.4\% were HER2-positive. Among the 1035 patients with a known progesterone receptor (PR) status, $67.1 \%$ were PR-positive. There were 520 women with molecular subtype information; $70.6 \%$ were luminal, $22.3 \%$ were basal-like, and $7.1 \%$ were HER2-enriched. The average follow-up in the 1086 patients with available follow-up information were 27.5 (range: 0-282.7) months. During the follow-up period, 154 patients died. 
BRCA1, CCND1, MHC-I, T cell activation- and exhaustionrelated genes

We retrieved the upper quartile normalized RNA-seq by Expectation Maximization (RNA-seq V2 RSEM) data from a TCGA breast invasive carcinoma study available at TCGA provisional (https://www.cbioportal.org/) accessed as of July, 2018 [27, 28]. Expression data of BRCA1, CCND1, MHC-I, antigen-presenting-related genes, and 13 genes related to $\mathrm{T}$ cell activation status $(8$ genes associated to $\mathrm{T}$ cell activation: NKG7, CCL4, CST7, PRF1, GZMA, GZMB, IFNG and CCL3, and 5 genes associated to $\mathrm{T}$ cell exhaustion: $P D-1$, TIGIT, LAG3, TIM3 and CTLA4) were available [9]. Experimental data generation and processing were previously described [29]. Gene expressions and clinicopathologic data were integrated, and the 1088 women patients with gene expression data were included in this study. No patients received neoadjuvant treatment.

\section{Statistical analyses}

A weighted $\mathrm{T}$ cell activation score was calculated for each subject based on 13 genes relevant to T cell activation status as described previously [26]. The overall survival was the time from surgery until death. Spearman correlation was used to evaluate correlations.

To investigate whether the BRCA1 and CCND1 expression modifies the effect of $\mathrm{T}$ cell activation status on patients' survival in breast cancer, we performed multivariate Cox proportional hazards models stratified by the BRCA1 or CCND1 level, where medians of the $B R C A 1$ and $C C N D 1$ expression levels were used as cutoff values. Three groups, high (activation), intermediate, and low (exhaustion), were defined based on the $\mathrm{T}$ cell activation score as previously described [26]. Patient's age at diagnosis, disease stage and histological type were included in the models to estimate adjusted hazards ratios (HRs) and their 95\% confidence intervals (95\% CIs). In the whole sample, we also assessed the interaction between $\mathrm{T}$ cell activation score and either BRCA1 or $C C N D 1$ levels by including their interactions in the Cox regression models. Proportional hazards assumption was examined. In all statistical analyses, a $p$ value less than 0.05 was considered significant. Statistical analyses were performed using SAS version 9.4 (SAS Institute, Inc).

\section{Results}

\section{Correlation between BRCA1 expression and T cell} activation score

Table 1 shows the distribution of $B R C A 1$ expression and $\mathrm{T}$ cell activation score, and their spearman correlation. In 1088 tumor tissues, the average $B R C A 1$ expression level was 340.5 Fragments Per Kilobase of transcript per Million mapped reads (FPKM) (variation: 302.3 FPKM; range: 8.54-2267 FPKM). The median of the T cell activation score was 1.71 (range: - 40.7 - 251). The BRCA1 expression was negatively correlated with the $\mathrm{T}$ cell activation score (correlation coefficient $=-0.13,95 \%$ CI: -0.19 $-0.08, p<0.0001)$.

\section{Correlation between CCND1 expression and, T-cell activation score, MHC-I and antigen-presenting related genes}

The distributions of CCND1, MHC-I molecules ( $H L A-A$, $B$ and $C$ ) and the antigen-presenting related genes (ERAP1 and ERAP2 for peptide cleavage, TAP1 and $T A P 2$ for peptide transportation, and TAPBP for transporter-MHC interactions) are shown in Table 2. CCND1 was negatively correlated with $\mathrm{T}$ cell activation score (correlation coefficient $=-0.17, p<0.0001$ ), HLA-A (correlation coefficient $=-0.26, p<0.0001), H L A-B$ (correlation coefficient $=-0.27, p<0.0001), H L A-C$ (correlation coefficient $=-0.21, p<0.0001$ ), ERAP2 (correlation coefficient $=-0.08, p=0.01$ ), TAP1 (correlation coefficient $=-0.26, \quad p<0.0001), \quad$ TAP2 (correlation coefficient $=-0.30, \quad p<0.0001$ ) and TAPBP (correlation coefficient $=-0.16, \quad p<0.0001)$. No correlation was found between the expression levels of CCND1 and ERAP1 $(p=0.109)$.

\section{Interaction between $\mathrm{T}$ cell activation status and either BRCA1 or CCND1 expression level in patient survival} In all the subgroups considered, the assumption of proportional hazards was verified based on 1000 simulations when testing the proportional hazards assumption ( $p=0.073$ in the low BRCA1 group, $p=0.381$ in the high $B R C A 1$ group, $p=0.688$ in the low $C C N D 1$ group, and $p=0.758$ in the high CCND1 group).

We investigated the relationship between survival and the $\mathrm{T}$ cell activation status (Activation, Intermediate, and

Table 1 Distribution of the BRCA1 gene expression and T cell activation score, and their spearman correlation

\begin{tabular}{llllll}
\hline Variable & $\mathrm{N}$ & Mean & $\mathrm{SD}^{\text {a }}$ & Median & Range \\
\hline BRCA1 & 1088 & 425.3 & 302.3 & 340.5 & $(8.5,2267)$ \\
$\begin{array}{l}\text { T cell activation score } \\
\text { Correlation coefficient }\left(95 \% \mathrm{Cl}^{\mathrm{b}}\right)\end{array}$ & 1088 & 5.84 & 17.2 & 1.71 & $(-40.7,251)$ \\
$p$-value & & & & -0.13 & $(-0.19,-0.08)$ \\
\hline
\end{tabular}


Table 2 Distribution of the CCND1, MHC-I and antigen-presenting related gene expression, and their spearman correlation

\begin{tabular}{|c|c|c|c|c|c|}
\hline \multirow[b]{2}{*}{ Variable } & \multirow[b]{2}{*}{ N } & \multirow[b]{2}{*}{ Median } & \multirow[b]{2}{*}{ Range } & \multicolumn{2}{|l|}{ CCND1 $(N=1088)$} \\
\hline & & & & Correlation (95\% Cl) & $p$ value \\
\hline T cell activation score & & & & $-0.17(-0.22,-0.11)$ & $<0.0001$ \\
\hline HLA-A & 1088 & 14,636 & $1290-186,441$ & $-0.26(-0.32,-0.21)$ & $<0.0001$ \\
\hline$H L A-B$ & 1088 & 22,385 & $2013-373,873$ & $-0.27(-0.33,-0.22)$ & $<0.0001$ \\
\hline HLA-C & 1088 & 16,592 & $1455-224,187$ & $-0.21(-0.26,-0.15)$ & $<0.0001$ \\
\hline ERAP1 & 1088 & 1416 & $94-7157$ & $0.05(-0.01,0.11)$ & 0.109 \\
\hline ERAP2 & 1088 & 643 & $4.5-6506$ & $-0.08(-0.14,-0.02)$ & 0.0098 \\
\hline TAP1 & 1088 & 2259 & $205-41,853$ & $-0.26(-0.31,-0.20)$ & $<0.0001$ \\
\hline TAP2 & 1088 & 1148 & $117-15,665$ & $-0.30(-0.35,-0.24)$ & $<0.0001$ \\
\hline TAPBP & 1088 & 5193 & $1307-24,371$ & $-0.16(-0.21,-0.10)$ & $<0.0001$ \\
\hline CCND1 & 1088 & 7925 & $129-245,328$ & & \\
\hline
\end{tabular}

Exhaustion) stratified by either the $B R C A 1$ or $C C N D 1$ expression levels. In the low $B R C A 1$ expression group, patients with a high $\mathrm{T}$ cell activation score (Activation) showed better overall survival compared to those with a low $\mathrm{T}$ cell activation score (Exhaustion) (Fig. 1a). The median of overall survival was 120.5 months (95\% CI: $77.1-\infty)$ in the Exhaustion group, 114.7 months (95\% CI: $112.3-\infty)$ in the Intermediate group, and 216.6 months (95\% CI: $97.4-\infty)$ in the Activation group, respectively. Patients in the Activation group lived on average 96.1 months longer than those in the Exhaustion group. The Activation group showed significantly decreased risk of death ( $\mathrm{p}$-trend $=0.027$ ) as compared to the Exhaustion group. The HRs of death were 0.60 (95\% CI: 0.35-1.00) for Intermediate vs Exhaustion, and 0.46 (95\% CI: 0.22-0.98) for Activation vs Exhaustion. In contrast, among the patients with a high $B R C A 1$ expression level, there was no significant difference in the overall survival between the Activation and Exhaustion groups (Fig. 1b). The median of overall survival was 129.5 months (95\% CI: $93.8-\infty$ ) for the Exhaustion group, 122.7 months (95\% CI: 83.8-146.4) for the Intermediate group, and 130.1 months (95\% CI: 114.1-244.9) for the Activation group, respectively. Patients in the Activation group lived on average 0.6 months longer than those in the Exhaustion group. The HRs of death were 1.55 (95\% CI: 0.89-2.65) for Intermediate vs Exhaustion, and 0.76 (95\% CI: 0.33-1.77) for Activation vs Exhaustion, respectively. No significant trend in the risk of death was found for the T cell activation status in the patients with a high BRCA1 expression level ( $\mathrm{p}$-trend $=0.898)$. In the whole sample, the interaction test suggested a significant interaction between BRCA1 expression level and $\mathrm{T}$ cell activation status $(p=0.043)$.

Figure 2 shows the Kaplan-Meier survival in three groups based on patients' $T$ cell activation status stratified by the CCND1 expression levels (low and high). In the low CCND1 expression group, improved overall survival was observed for patients in the Activation vs. the Exhaustion group (Fig. 2a). The median of overall survival was 120.5 months (95\% CI: $91.9-\infty$ ) for the Exhaustion group, the median survival did not reach (95\% CI: $102.7-\infty)$ for the Intermediate group, and 216.6 months (95\% CI: $114.1-\infty)$ for the Activation group, respectively. Patients in the Activation group lived on average 96.1 months longer than those in the Exhaustion group. The Activation group showed significantly decreased risk of death (p-trend $=0.015$ ) as compared to the Exhaustion group. The HRs of death were 0.72 (95\% CI: $0.44-1.17)$ for Intermediate vs Exhaustion, and 0.43 (95\% CI: 0.21-0.86) for Activation vs Exhaustion. In contrast, in the patients with a high CCND1 expression level, there was no significant difference in the overall survival between the Activation and Exhaustion groups (Fig. 2b). The median of overall survival was 129.5 months (95\% CI: $97.4-\infty$ ) for the Exhaustion group, 122.7 months (95\% CI: $112.0-146.4$ ) for the Intermediate group, and 130.1 months (95\% CI: 100.6-244.9) for the Activation group, respectively. The Activation group lived approximately 0.6 months longer than the Exhaustion group. The HRs of death were 1.41 (95\% CI: 0.77-2.60) for Intermediate vs Exhaustion, and 0.92 (95\% CI: 0.36-2.32) for Activation vs Exhaustion, respectively. No significant trend in the risk of death was found for the $\mathrm{T}$ cell activation status in the patients with a high CCND1 expression level ( $\mathrm{p}$-trend $=0.881$ ). In the whole sample, there is no significant interaction between CCND1 expression level and T cell activation status $(p=0.143)$.

We then performed multivariate Cox proportional hazards models to adjust for potential confounding variables including patient's age at surgery, disease stage, tumor grade and histological types. Results are shown in Tables 3 and 4. Similarly, the association remained significant between the $\mathrm{T}$ cell activation status and death risk in the patients with a low BRCA1 expression level 

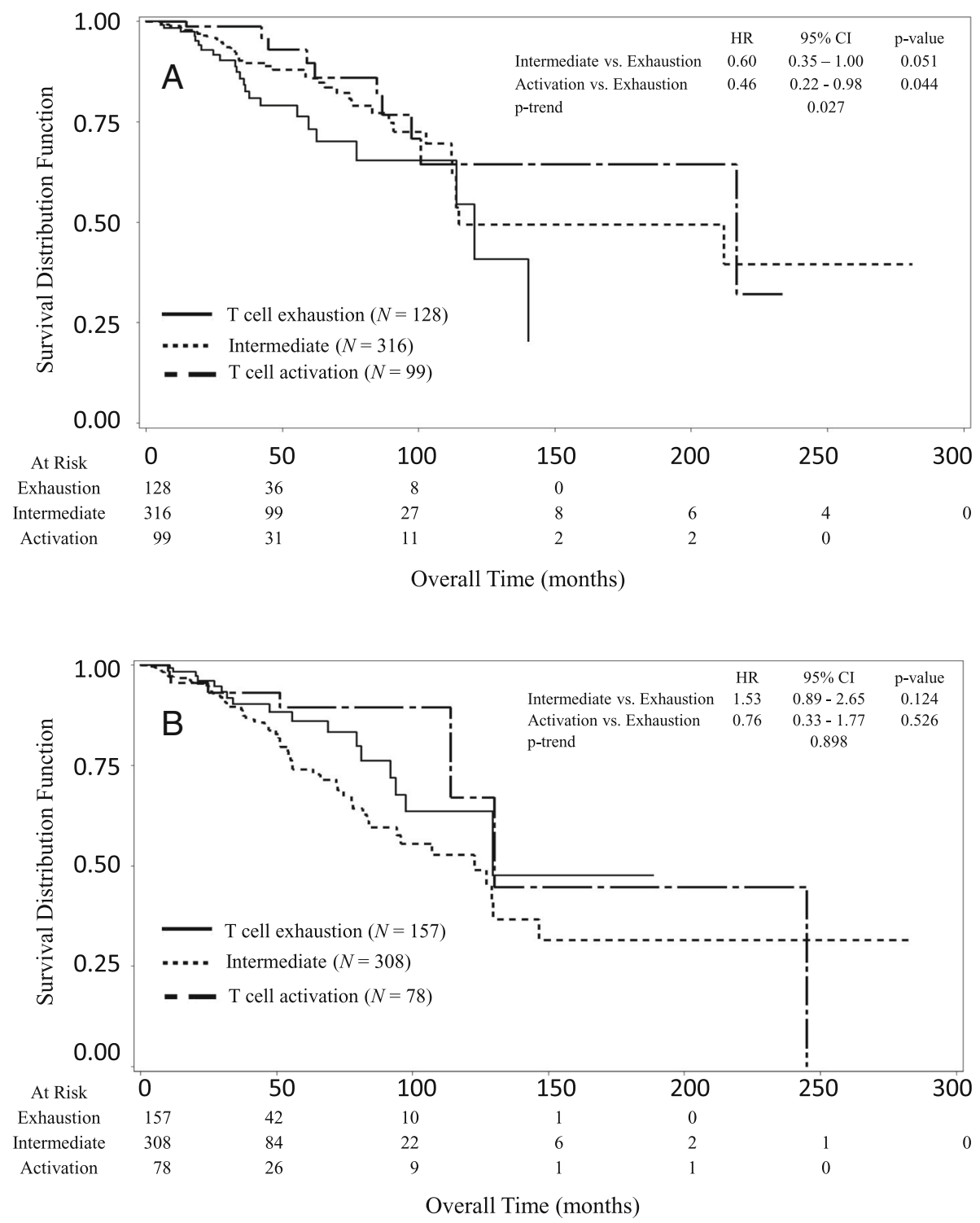

Fig. 1 Kaplan-Meier survival curves of breast cancer patients stratified by the T cell activation status (score). a In the subgroup with a low BRCA1 expression level, patients in the Activation group had better overall survival compared to those in the Exhaustion group $(p$-trend $=0.027)$. $\mathbf{b}$ In the subgroup with a high BRCA1 expression level, there were no significant difference in overall survival between patients in the Activation and Exhaustion groups ( $\mathrm{p}$-trend $=0.898$ )

(Table 3). The adjusted HRs were 0.47 (95\% CI: $0.28-$ 0.80 ) for Intermediate vs Exhaustion, and 0.43 (95\% CI: 0.20-0.93) for Activation vs Exhaustion, respectively. T cell activation score was negatively associated with the death risk ( $\mathrm{p}$-trend $=0.011$ ). In contrast, among the patients with a high BRCA1 expression level, there was no significant association or linear relationship (p-trend $=0.640$ ) between the $\mathrm{T}$ cell activation status and death risk. The adjusted HRs were 1.47 (95\% CI: 0.85-2.55) for Intermediate vs Exhaustion, and 0.53 (95\% CI: 0.201.43) for Activation vs Exhaustion, respectively. Again, the interaction test in the whole sample showed a significant interaction between BRCA1 level and T cell activation status $(p=0.009)$ after adjustment for the covariates. Similarly, among the patients with a low CCND1 expression level, a high $\mathrm{T}$ cell activation score decreased mortality risk (Table 4). The adjusted HRs were 0.67 (95\% CI: $0.41-1.10)$ for Intermediate vs Exhaustion, and 0.39 (95\% CI: 0.19-0.81) for Activation vs Exhaustion, respectively. $\mathrm{T}$ cell activation score was negatively associated with the death risk ( $\mathrm{p}$-trend = 0.008). In contrast, among the patients with a high CCND1 expression level, there was no significant association or linear relationship ( $p$-trend $=0.882$ ) between the 

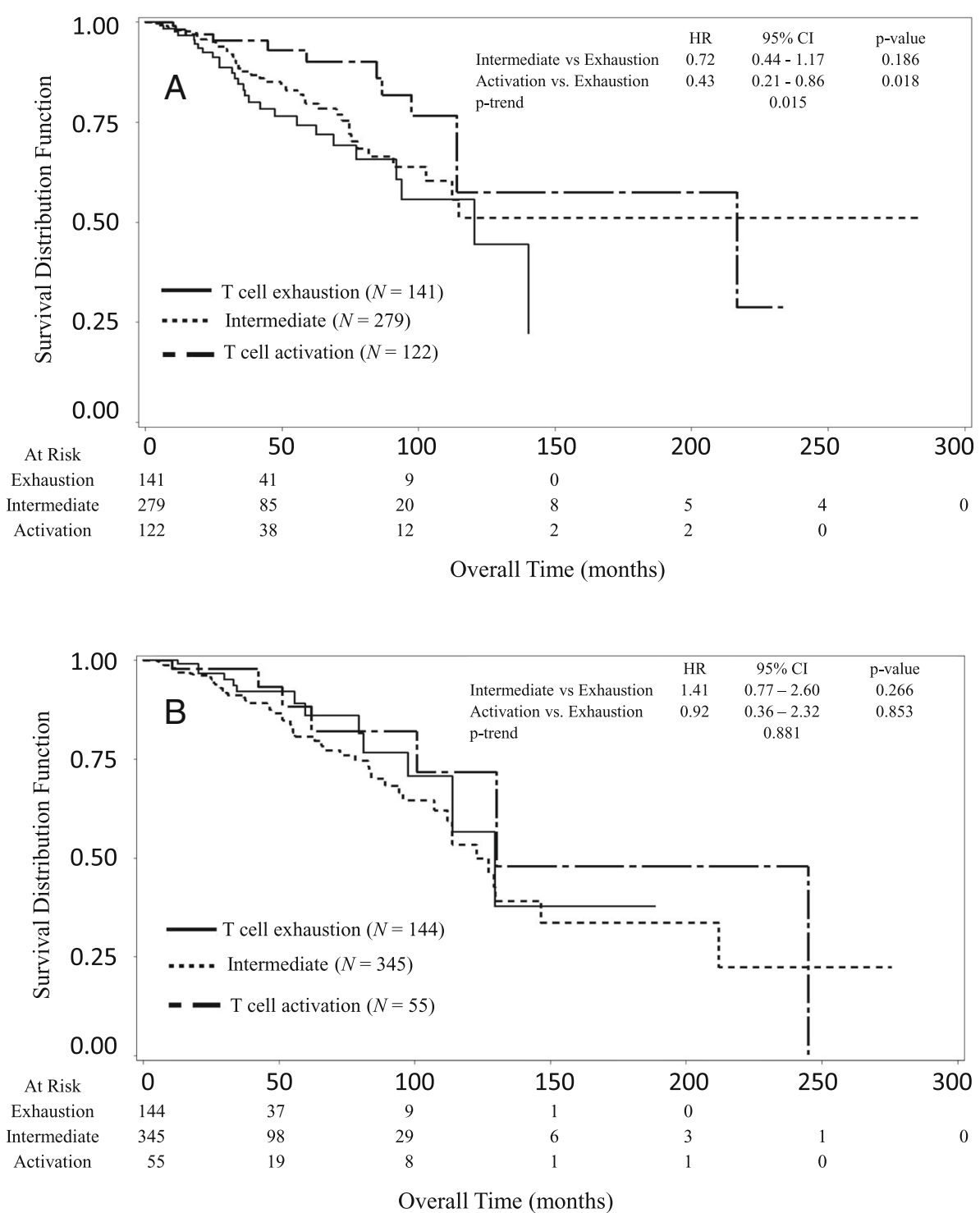

Fig. 2 Kaplan-Meier survival curves of breast cancer patients stratified by the T cell activation status (score). a In the subgroup with a low CCND1 expression level, patients in the Activation group had better overall survival compared to those in the Exhaustion group $(p$-trend $=0.015)$. $\mathbf{b}$ In the subgroup with a high CCND1 expression level, there were no significant difference in overall survival between patients in the Activation and Exhaustion groups ( $\mathrm{p}$-trend $=0.881$ )

T cell activation status and death risk. The adjusted HRs were 1.34 (95\% CI: $0.73-2.47)$ for Intermediate vs Exhaustion, and 0.91 (95\% CI: 0.33-2.52) for Activation vs Exhaustion, respectively. Similarly, the interaction test in the whole sample showed no significant interaction between CCND1 level and $\mathrm{T}$ cell activation status $(p=0.135)$ after adjustment for the covariates.

\section{Discussion}

In this study, we investigated the relationships between the BRCA1 expression and the $\mathrm{T}$ cell activation score, between CCND1 and MHC-I molecules and antigen-presenting related genes, as well as the interaction between either the BRCA1 or CCND1 expression and the T cell activation status in breast cancer patient survival. Based on data in a cohort of 1088 patients with primary breast cancer, our analysis results suggested that there was a negative correlation between the BRCA1 expression and the $\mathrm{T}$ cell activation score. In the subgroup with a low BRCA1 expression level, patients with a high $\mathrm{T}$ cell activation score lived 96.1 months longer than those with a low $\mathrm{T}$ cell activation score, whereas in the subgroup with a high $B R C A 1$ expression level, patients with a high $\mathrm{T}$ cell activation score survived 0.6 months longer than those with a low $\mathrm{T}$ cell activation score. CCND1 was negatively correlated with $\mathrm{T}$ cell 
Table 3 Association of the T cell activation status and mortality of breast cancer stratified by the BRCA1 expression level

\begin{tabular}{|c|c|c|c|c|}
\hline \multirow{2}{*}{$\begin{array}{l}\text { Stratification } \\
\text { Variable }\end{array}$} & \multirow[b]{2}{*}{ Variable } & \multicolumn{3}{|c|}{ Death } \\
\hline & & $\overline{\mathrm{HR}^{\mathrm{a}}}$ & $95 \% \mathrm{Cl}^{\mathrm{b}}$ & $p$-value \\
\hline \multirow[t]{12}{*}{ Low BRCA1 } & T cell activation & & & \\
\hline & Exhaustion & 1.00 & & \\
\hline & Intermediate & 0.47 & $0.28-0.80$ & 0.006 \\
\hline & Activation & 0.43 & $0.20-0.93$ & 0.031 \\
\hline & $\mathrm{p}$-trend & & 0.011 & \\
\hline & Age (per 5 years) & 1.15 & $1.05-1.27$ & 0.004 \\
\hline & Disease Stage & 2.78 & $1.89-4.10$ & $<0.0001$ \\
\hline & Histological type & & & \\
\hline & Ductal & 1.00 & & \\
\hline & Lobular & 0.54 & $0.29-1.00$ & 0.048 \\
\hline & Mix & 0.81 & $0.29-2.28$ & 0.683 \\
\hline & Other & 2.36 & $0.92-6.03$ & 0.074 \\
\hline \multirow[t]{12}{*}{ High BRCA1 } & $\mathrm{T}$ cell activation & & & \\
\hline & Exhaustion & 1.00 & & \\
\hline & Intermediate & 1.47 & $0.85-2.55$ & 0.174 \\
\hline & Activation & 0.53 & $0.20-1.43$ & 0.211 \\
\hline & $\mathrm{p}$-trend & & 0.640 & \\
\hline & Age (per 5 years) & 1.23 & $1.13-1.35$ & $<0.0001$ \\
\hline & Disease Stage & 2.07 & $1.45-2.96$ & $<0.0001$ \\
\hline & Histological type & & & \\
\hline & Ductal & 1.00 & & \\
\hline & Lobular & 0.77 & $0.39-1.52$ & 0.448 \\
\hline & Mix & 0.68 & $0.25-1.87$ & 0.450 \\
\hline & Other & 2.79 & $1.09-7.13$ & 0.032 \\
\hline \multicolumn{2}{|c|}{$\begin{array}{l}P \text {-value for the interaction between } B R C A 1 \\
\text { level and T cell activation }\end{array}$} & & 0.009 & \\
\hline
\end{tabular}

aHR: adjusted hazard ratio, which was obtained from a multivariate Cox proportional hazards regression model

${ }^{\mathrm{b}} \mathrm{Cl}$ confidence interval

activation score, the MHC-I molecules (HLA-A, $H L A-B, H L A-C)$, peptide transporter genes TAP1 and TAP2 expression, TAP binding protein gene TAPBP and peptide cleavage gene ERAP2 expression. These findings agree with the report by Goel and colleagues [24], suggesting that $\mathrm{MHC}-\mathrm{I}$ and antigen presenting-associated genes are high in the low CCND1 expression group, and more antigens may be presented. Furthermore, in the subgroup with a low $C C N D 1$ expression level, patients in the Activation group lived 96.1 months longer than those in the Exhaustion group. However, in the subgroup with a high CCND1 expression level, patients in the Activation group survived approximately 0.6 months longer than the Exhaustion group.

Genomic instability is a hallmark of human cancer and plays an important role in cancer initiation and
Table 4 Association of the T cell activation status and mortality of breast cancer stratified by the CCND1 expression level

\begin{tabular}{|c|c|c|c|c|}
\hline \multirow{2}{*}{$\begin{array}{l}\text { Stratification } \\
\text { Variable }\end{array}$} & \multirow[b]{2}{*}{ Variable } & \multicolumn{3}{|c|}{ Death } \\
\hline & & $H R^{a}$ & $95 \% \mathrm{Cl}^{\mathrm{b}}$ & $p$-value \\
\hline \multirow[t]{12}{*}{ Low CCND1 } & $\mathrm{T}$ cell activation & & & \\
\hline & Exhaustion & 1.00 & & \\
\hline & Intermediate & 0.67 & $0.41-1.10$ & 0.113 \\
\hline & Activation & 0.39 & $0.19-0.81$ & 0.011 \\
\hline & $\mathrm{p}$-trend & & 0.008 & \\
\hline & Age (per 5 years) & 1.14 & $1.04-1.25$ & 0.008 \\
\hline & Disease Stage & 2.77 & $1.89-4.07$ & $<.0001$ \\
\hline & Histological type & & & \\
\hline & Ductal & 1.00 & & \\
\hline & Lobular & 0.61 & $0.34-1.12$ & 0.109 \\
\hline & Mix & 1.44 & $0.57-3.62$ & 0.441 \\
\hline & Other & 3.01 & $1.32-6.83$ & 0.009 \\
\hline \multirow[t]{12}{*}{ High CCND1 } & $\mathrm{T}$ cell activation & & & \\
\hline & Exhaustion & 1.00 & & \\
\hline & Intermediate & 1.34 & $0.73-2.47$ & 0.352 \\
\hline & Activation & 0.91 & $0.33-2.52$ & 0.854 \\
\hline & $\mathrm{p}$-trend & & 0.822 & \\
\hline & Age (per 5 years) & 1.26 & $1.15-1.38$ & $<.0001$ \\
\hline & Disease Stage & 2.09 & $1.47-2.98$ & $<.0001$ \\
\hline & Histological type & & & \\
\hline & Ductal & 1.00 & & \\
\hline & Lobular & 0.69 & $0.35-1.36$ & 0.281 \\
\hline & Mix & 0.38 & $0.12-1.23$ & 0.106 \\
\hline & Other & 1.44 & $0.49-4.24$ & 0.509 \\
\hline \multicolumn{2}{|c|}{$\begin{array}{l}P \text { value for the interaction between CCND1 } \\
\text { level and T cell activation }\end{array}$} & & 0.135 & \\
\hline
\end{tabular}

aHR: adjusted hazard ratio, which was obtained from a multivariate Cox proportional hazards regression model

${ }^{\mathrm{b}} \mathrm{Cl}$ confidence interval

progression. This instability leads to the susceptibility of genomic DNA to genotoxic stress, which in turn results in DNA damage, including single-base DNA sequence changes, and structural (insertion/deletion) and copy number abnormalities. If DNA damage occurs, cell cycle will arrest and subsequently triggers DNA damage repair systems. With a high fidelity repair for DNA damage, genome integrity can be preserved and thereby prevents the potential of cancer initiation. However, in case of deficiency in DNA damage repair pathways, alterations of DNA sequences can occur which drives aberrant expression of oncogenes and tumor suppressor genes, and consequently results in tumors. As a key player in the homologous recombination-based DNA repair pathway, $B R C A 1$ acts as a tumor suppressor via maintaining genome integrity. Both DNA mutations and 
epigenetic silence can lead to the loss of function of $B R C A 1$ which are associated with human cancer including breast [30-32]. Indeed, epigenetic perturbation is a risk factor in patient survival of diverse cancer types [33, 34]. Interestingly, both $B R C A 1$ promoter hypermethylated tumors and $B R C A 1$ mutated tumors share similar characteristics such as low $\mathrm{pRb}$ expression and being associated with basal/triple-negative subtype of breast cancer [35]. Birkbak et al. [36] reported that a higher number of DNA mutations were observed in $B R C A 1$-mutated tumors in comparison to BRCA1-wild type tumors. Alexandrov et al. [37] demonstrated that a large number of insertion and deletion with overlapping microhomology at break point junctions were strongly associated with $B R C A 1$ mutations in breast cancer. Nolan and colleagues showed that in BRCA1-mutated triple-negative breast cancers (TNBCs), both mutational loads and the numbers of TIL significantly increased with the accompanying elevation of PD-1 and CTLA4 expression compared to those in the BRCA1-wild type one [38]. They also found that the genotoxic cisplatin treatment augmented anti-PD-1/anti-CTLA4 immunotherapy in Brca1-deficient mice [38]. The elevated DNA mutations in BRCA1-deficient tumors is due to the low fidelity Pol /PARP1-based alternative non-homologous end-jointing pathways for double-stranded DNA damage repair $[39,40]$. It has been reported that high neoantigene loads were associated with BRCA1 mutation and microsatellite instability $[41,42]$. These neoantigenes act as foreign peptides to activate host immune systems. Thus, the finding in this study that the BRCA1 expression level was inversely correlated with the $\mathrm{T}$ cell activation score provides extensive clinical evidence, supporting the proof of concept that BRCA1 deficiency (either mutation- or hypermethylation-induced) leads to increased potential neoantigens, which consequently activate $\mathrm{T}$ cells. It will be interesting to further explore how a BRCA1 mutation, given that the inherit BRCA1 mutations significantly increase the lifetime risk of developing breast and/or ovarian cancer, affect the effect of $\mathrm{T}$ cell activation status on patient survival in breast cancer in future studies when the information is available.

After the processing of somatic mutation-derived neoantigens by antigen presenting cells (APCs), the complex of MHC class I molecules and neoantigen-peptides then primes and educates effector $\mathrm{CD}^{+} \mathrm{T}$ cells, then activates the effector cells. Neoantigens on tumor cells determine which activated $\mathrm{CD}^{+}{ }^{+} \mathrm{T}$ cells are recognized and eliminate tumor cells. Low BRCA1 results in hypermutation in tumor cells and generates more somatic alterations in DNA and protein sequences with antigen potential. The enhancement of antigen presentation, for example, using Calreticulin (CRT), increases immune response [43, 44]. The upregulation of antigen processing and presentation-related genes is enriched, and serves as an underlying molecular mechanism of the anti-tumor immunity triggered by the CDK4/6 inhibitors in the animal models [24]. In line with this proof of concept, we found that in patients with a low expression level of either $B R C A 1$ or $C C N D 1$, the $\mathrm{T}$ cell activation score is negatively associated with the risk of mortality in breast cancer. Over $50 \%$ reduction in the risk of mortality $(\mathrm{HR}=0.47$ in patients with a low $B R C A 1 \mathrm{ex}-$ pression level) was observed in patients with an intermediate $\mathrm{T}$ cell activation score, and in patients with a high $\mathrm{T}$ cell activation score $(\mathrm{HR}=0.43$ in patients with a low $B R C A 1$ expression level; $\mathrm{HR}=0.42$ in patients with a low CCND1 expression level), compared to those with a low $\mathrm{T}$ cell activation score. Patients in the Activation group survived over 8 years longer than those in the Exhaustion group if they had a low level of $B R C A 1$ expression. In contrast, in patients with a high level of $B R C A 1$ expression, there was no significant association between the $\mathrm{T}$ cell activation score and the risk of mortality. The median survival were similar for three subgroups, Exhaustion, Intermediate and Activation. This finding suggests that the increase of neoepitopes (neoantigens) and the enhancement of antigen presentation can be utilized in immunotherapies in combination with immune checkpoint blockade, it could improve patient survival. The results from other studies and ours show that PLGA-nanoparticle-mediated delivery of tumor antigenic peptides effectively induce cytotoxic $\mathrm{T}$ cell responses and destroy tumor cells [45-48]. Virus-based tumor antigen delivery has been also extensively investigated. Osada and colleagues [49] recently demonstrated that recombinant adenoviral vectors encoding human HER3 substantially induced the TILs in tumors, elicited HER3-specific T cells and influenced the host response to immune checkpoint blockers.

Using the Genomics-driven immunoproteomics (GDI) approach that combines deep genomic sequencing and personalized immune assessment platform, 149 tumor antigens were discovered from breast cancer patients [50]. These putative neoantigens were derived from single nucleotides mutations, insertion and deletion. The high-throughput next-generation genome sequence in combination with personalized peptide array may be able to expedite tumor-associated antigenic peptide identification, and help design novel effective cancer vaccines by delivering tumor-specific neoepitopes to improve the efficacy of immune checkpoint-based immunotherapies. Recently, two clinical trials were carried out to evaluate the efficacy of tumor-specific neoantigens in patients with melanoma $[51,52]$. The neoantigens were synthesized long peptides, which were predicted tumor-derived epitopes with a high affinity to bind MHC class I molecule based on a somatic 
mutation-related novel protein sequences using an algorithm. They found that the neoantigens activated effector $\mathrm{T}$ cells and substantial immune responses were observed in patients. Over $50 \%$ of patients (4 of 6 and 8 of 13 , respectively) showed tumor free throughout the follow-up period (32 months and 12-23 months, respectively) after the vaccination. Tumor recurrence occurred in the remaining patients in both studies, however, who had well responded to the PD-1 inhibitor.

Studies have shown that TILs are one of the favorable prognostic markers in triple-negative or $\mathrm{HER}^{+}$breast cancer patients, but not in those with $\mathrm{ER}^{+} / \mathrm{HER} 2^{-}$ [53-57]. Tomioka and colleagues reported that unfavorable prognosis was observed in triple-negative breast cancer with low TILs and high PD-L1 [58]. Understanding the factor(s) stimulating TILs may help to design novel strategies in switching 'cold-' to 'hot-' tumors. Recently, animal models showed that the RNA-editing induced RNA structure switching from single-strand RNA (ssRNA) to dsRNA could increase tumor inflammation and thereby overcome PD-1 blockade resistance [59]. The number of TILs significantly increased in BRCA1-mutated breast cancer tumors than the wild-type ones [38], suggesting that loss of BRCA1 function might elicit tumor inflammation. However, the underlying mechanism(s) is yet to be determined. Given that the abundance and compositions of TILs are important in cancer immunotherapy, it warrants to further investigate how the TIL abundance and composition affect $\mathrm{T}$ cell activation and what factor(s) influences its abundance and composition.

\section{Conclusions}

This is the first study to demonstrate the association of the BRCA1 expression level and the $\mathrm{T}$ cell activation score, and their interaction in patient survival in breast cancer. The $\mathrm{T}$ cell activation score was negatively associated with the BRCA1 expression and the CCND1 expression and the expressions of MHC-I molecules and antigen presenting related genes. In the subgroup of patients with low but not high levels of either $B R C A 1$ or CCND1 expression, high $\mathrm{T}$ cell activation score significantly reduced the risk of mortality. These findings suggest that immune checkpoint inhibitors will benefit patients by reinvigorating effector $\mathrm{T}$ cells if they are either BRCA1-deficient or CCND1-low. Inhibition of $B R C A 1$ and $C C N D 1$ genes may improve immune response by increasing neoantigens and their presentation. Tumor-specific neoantigen vaccine therapy and their efficient presentation may enhance patients' response to immune checkpoint therapies. More studies with a larger sample size are warranted to further examine how the different molecular subtypes of breast cancer affect the interaction of BRCA1 and CCND1 with T cell activation in patient survival.

\section{Acknowledgements}

We thank three anonymous reviewers for their thoughtful and constructive comments to improve the manuscript.

\section{Funding}

This study was supported by the National Institutes of Health $(\mathrm{NIH})$ grant K01AA023321. However, the funding body has no role in the design of the study and collection, analysis, and interpretation of data and in writing the manuscript.

\section{Availability of data and materials}

The data that support the findings of this study are available from breast invasive carcinoma (TCGA, Provisional) at cBioPortal for Cancer Genomics (https://www.cbioportal.org).

\section{Authors' contributions}

$L L$ was responsible for the conception and design of this study. $L L, H H$ and ZW collected and assembled data, and performed data analysis. LL and ZW wrote the manuscript. All authors contributed to the interpretation of results. All authors read and approved the final manuscript.

\section{Ethics approval and consent to participate}

No formal consent is required for this type of study. The ethical standards of the institutional and/or national research committee and with the 1964 Helsinki declaration and its later amendments or comparable ethical standards were followed in performing all procedures in this study involving human subjects. The study presented here complies with the current laws of the United States of America.

\section{Consent for publication}

Not applicable.

\section{Competing interests}

The authors declare that they have no competing interests.

\section{Publisher's Note}

Springer Nature remains neutral with regard to jurisdictional claims in published maps and institutional affiliations.

\section{Author details}

'Department of Chronic Disease Epidemiology, Yale School of Public Health, School of Medicine, Center for Biomedical Data Science, Yale Cancer Center, Yale University, 60 College Street, New Haven, CT 06520-8034, USA. ${ }^{2}$ Guizhou Qianxinan People's Hospital, Xingyi 652400, Guizhou, China. ${ }^{3}$ Isoplexis Corporation, 35 NE Industrial Road, Branford, CT 06405, USA. ${ }^{4}$ Moores Cancer Center, University of California San Diego, La Jolla, CA 92093, USA.

${ }^{5}$ Department of Biostatistics, Yale School of Public Health, School of Medicine, Center for Biomedical Data Science, Yale Cancer Center, Yale University, 60 College Street, New Haven, CT 06520-8034, USA.

Received: 8 October 2018 Accepted: 9 April 2019

Published online: 25 April 2019

\section{References}

1. Ruffell B, Au A, Rugo HS, Esserman LJ, Hwang ES, Coussens LM. Leukocyte composition of human breast cancer. Proc Natl Acad Sci U S A. 2012;109(8): 2796-801.

2. Savas P, Salgado R, Denkert C, Sotiriou C, Darcy PK, Smyth MJ, Loi S. Clinical relevance of host immunity in breast cancer: from TILs to the clinic. Nat Rev Clin Oncol. 2016;13(4):228-41.

3. Turajlic S, Litchfield K, Xu H, Rosenthal R, McGranahan N, Reading JL, Wong YNS, Rowan A, Kanu N, Al Bakir M, et al. Insertion-and-deletion-derived tumour-specific neoantigens and the immunogenic phenotype: a pancancer analysis. Lancet Oncol. 2017;18(8):1009-21.

4. Gubin MM, Zhang X, Schuster H, Caron E, Ward JP, Noguchi T, Ivanova Y, Hundal J, Arthur CD, Krebber WJ, et al. Checkpoint blockade cancer immunotherapy targets tumour-specific mutant antigens. Nature. 2014; 515(7528):577-81.

5. Prickett TD, Crystal JS, Cohen CJ, Pasetto A, Parkhurst MR, Gartner JJ, Yao X, Wang R, Gros A, Li YF, et al. Durable complete response from metastatic melanoma after transfer of autologous $T$ cells recognizing 10 mutated tumor antigens. Cancer Immunol Res. 2016;4(8):669-78. 
6. Klebanoff CA, Rosenberg SA, Restifo NP. Prospects for gene-engineered T cell immunotherapy for solid cancers. Nat Med. 2016;22(1):26-36.

7. Wang RF, Wang HY. Immune targets and neoantigens for cancer immunotherapy and precision medicine. Cell Res. 2017;27(1):11-37.

8. Newick K, Moon E, Albelda SM. Chimeric antigen receptor T-cell therapy for solid tumors. Mol Ther Oncolytics. 2016;3:16006.

9. Tirosh I, Izar B, Prakadan SM, Wadsworth MH 2nd, Treacy D, Trombetta JJ, Rotem A, Rodman C, Lian C, Murphy G, et al. Dissecting the multicellular ecosystem of metastatic melanoma by single-cell RNA-seq. Science. 2016; 352(6282):189-96.

10. Chen L, Han X. Anti-PD-1/PD-L1 therapy of human cancer: past, present, and future. J Clin Invest. 2015;125(9):3384-91.

11. Nanda R, Chow LQ, Dees EC, Berger R, Gupta S, Geva R, Pusztai L, Pathiraja K, Aktan G, Cheng JD, et al. Pembrolizumab in patients with advanced triple-negative breast cancer: phase Ib KEYNOTE-012 study. J Clin Oncol. 2016;34(21):2460-7.

12. Fourcade J, Sun Z, Pagliano O, Guillaume P, Luescher IF, Sander C, Kirkwood JM, Olive D, Kuchroo V, Zarour HM. CD8(+) T cells specific for tumor antigens can be rendered dysfunctional by the tumor microenvironment through upregulation of the inhibitory receptors BTLA and PD-1. Cancer Res. 2012;72(4):887-96.

13. Wherry EJ. T cell exhaustion. Nat Immunol. 2011;12(6):492-9.

14. Le DT, Uram JN, Wang H, Bartlett BR, Kemberling H, Eyring AD, Skora AD, Luber BS, Azad NS, Laheru D, et al. PD-1 blockade in tumors with mismatchrepair deficiency. N Engl J Med. 2015;372(26):2509-20.

15. Hugo W, Zaretsky JM, Sun L, Song C, Moreno BH, Hu-Lieskovan S, BerentMaoz B, Pang J, Chmielowski B, Cherry G, et al. Genomic and Transcriptomic features of response to anti-PD-1 therapy in metastatic melanoma. Cell. 2016;165(1):35-44.

16. Le DT, Durham JN, Smith KN, Wang H, Bartlett BR, Aulakh LK, Lu S, Kemberling H, Wilt C, Luber BS, et al. Mismatch-repair deficiency predicts response of solid tumors to PD-1 blockade. Science. 2017;357(6349):409-13.

17. Czink E, Kloor M, Goeppert B, Froehling S, Uhrig S, Weber TF, Meinel J, Sutter $C$, Weiss KH, Schirmacher $P$, et al. Successful immune checkpoint blockade in a patient with advanced stage microsatellite unstable biliary tract cancer. Cold Spring Harb Mol Case Stud. 2017:3(5):a001974.

18. Gong J, Wang C, Lee PP, Chu P, Fakih M. Response to PD-1 blockade in microsatellite stable metastatic colorectal Cancer harboring a POLE mutation. J Natl Compr Cancer Netw. 2017;15(2):142-7.

19. Johanns TM, Miller CA, Dorward IG, Tsien C, Chang E, Perry A, Uppaluri R, Ferguson C, Schmidt RE, Dahiya S, et al. Immunogenomics of Hypermutated Glioblastoma: a patient with Germline POLE deficiency treated with checkpoint blockade immunotherapy. Cancer Discov. 2016;6(11):1230-6.

20. O'Donovan PJ, Livingston DM. BRCA1 and BRCA2: breast/ovarian cancer susceptibility gene products and participants in DNA double-strand break repair. Carcinogenesis. 2010;31(6):961-7.

21. Konishi H, Mohseni M, Tamaki A, Garay JP, Croessmann S, Karnan S, Ota A, Wong HY, Konishi Y, Karakas B, et al. Mutation of a single allele of the cancer susceptibility gene BRCA1 leads to genomic instability in human breast epithelial cells. Proc Natl Acad Sci U S A. 2011;108(43):17773-8.

22. Alvarez C, Tapia T, Perez-Moreno E, Gajardo-Meneses P, Ruiz C, Rios M, Missarelli C, Silva M, Cruz A, Matamala L, et al. BRCA1 and BRCA2 founder mutations account for $78 \%$ of germline carriers among hereditary breast cancer families in Chile. Oncotarget. 2017;8(43):74233-43.

23. Green AR, Aleskandarany MA, Ali R, Hodgson EG, Atabani S, De Souza K, Rakha EA, Ellis IO, Madhusudan S. Clinical impact of tumor DNA repair expression and T-cell infiltration in breast cancers. Cancer Immunol Res. 2017;5(4):292-9.

24. Goel S, DeCristo MJ, Watt AC, BrinJones H, Sceneay J, Li BB, Khan N Ubellacker JM, Xie S, Metzger-Filho O, et al. CDK4/6 inhibition triggers antitumour immunity. Nature. 2017:548(7668):471-5.

25. Polk A, Kolmos IL, Kumler I, Nielsen DL. Specific CDK4/6 inhibition in breast cancer: a systematic review of current clinical evidence. ESMO Open. 2016; 1(6):e000093.

26. Lu L, Bai Y, Wang Z. Elevated T cell activation score is associated with improved survival of breast cancer. Breast Cancer Res Treat. 2017;164:689-96.

27. Cancer Genome Atlas N. Comprehensive molecular portraits of human breast tumours. Nature. 2012;490(7418):61-70.

28. Gao J, Aksoy BA, Dogrusoz U, Dresdner G, Gross B, Sumer SO, Sun Y, Jacobsen A, Sinha $R$, Larsson $E$, et al. Integrative analysis of complex cancer genomics and clinical profiles using the cBioPortal. Sci Signal. 2013;6(269):pl1.
29. Cancer Genome Atlas Research N. Comprehensive molecular characterization of gastric adenocarcinoma. Nature. 2014:513(7517):202-9.

30. Vos S, Moelans CB, van Diest PJ. BRCA promoter methylation in sporadic versus BRCA germline mutation-related breast cancers. Breast Cancer Res. 2017;19(1):64.

31. Antoniou A, Pharoah PD, Narod S, Risch HA, Eyfjord JE, Hopper JL, Loman N, Olsson $\mathrm{H}$, Johannsson $\mathrm{O}$, Borg A, et al. Average risks of breast and ovarian cancer associated with BRCA1 or BRCA2 mutations detected in case series unselected for family history: a combined analysis of 22 studies. Am J Hum Genet. 2003;72(5):1117-30.

32. Begg CB, Haile RW, Borg A, Malone KE, Concannon P, Thomas DC, Langholz $B$, Bernstein L, Olsen JH, Lynch CF, et al. Variation of breast cancer risk among BRCA1/2 carriers. JAMA. 2008;299(2):194-201.

33. Zhang L, Liu Y, Wang M, Wu Z, Li N, Zhang J, Yang C. EZH2-, CHD4-, and IDH-linked epigenetic perturbation and its association with survival in glioma patients. J Mol Cell Biol. 2017;9(6):477-88

34. Corces-Zimmerman MR, Hong WJ, Weissman IL, Medeiros BC, Majeti R. Preleukemic mutations in human acute myeloid leukemia affect epigenetic regulators and persist in remission. Proc Natl Acad Sci U S A. 2014;111(7): 2548-53.

35. Stefansson OA, Jonasson JG, Olafsdottir K, Hilmarsdottir $\mathrm{H}$, Olafsdottir $\mathrm{G}$, Esteller M, Johannsson OT, Eyfjord JE. CpG island hypermethylation of BRCA1 and loss of pRb as co-occurring events in basal/triple-negative breast cancer. Epigenetics. 2011;6(5):638-49.

36. Birkbak NJ, Kochupurakkal B, Izarzugaza JM, Eklund AC, Li Y, Liu J, Szallasi Z, Matulonis UA, Richardson AL, Iglehart JD, et al. Tumor mutation burden forecasts outcome in ovarian cancer with BRCA1 or BRCA2 mutations. PLoS One. 2013;8(11):e80023.

37. Alexandrov LB, Nik-Zainal S, Wedge DC, Aparicio SA, Behjati S, Biankin AV, Bignell GR, Bolli N, Borg A, Borresen-Dale AL, et al. Signatures of mutational processes in human cancer. Nature. 2013;500(7463):415-21.

38. Nolan E, Savas P, Policheni AN, Darcy PK, Vaillant F, Mintoff CP, Dushyanthen S, Mansour M, Pang JB, Fox SB, et al. Combined immune checkpoint blockade as a therapeutic strategy for BRCA1-mutated breast cancer. Sci Transl Med. 2017;9(393):eaal4922.

39. Ceccaldi R, Liu JC, Amunugama R, Hajdu I, Primack B, Petalcorin MI, O'Connor KW, Konstantinopoulos PA, Elledge SJ, Boulton SJ, et al. Homologous-recombination-deficient tumours are dependent on Polthetamediated repair. Nature. 2015;518(7538):258-62.

40. Mateos-Gomez PA, Gong F, Nair N, Miller KM, Lazzerini-Denchi E, Sfeir A. Mammalian polymerase theta promotes alternative NHEJ and suppresses recombination. Nature. 2015:518(7538):254-7.

41. Strickland KC, Howitt BE, Shukla SA, Rodig S, Ritterhouse LL, Liu JF, Garber JE, Chowdhury D, Wu CJ, D'Andrea AD, et al. Association and prognostic significance of BRCA1/2-mutation status with neoantigen load, number of tumor-infiltrating lymphocytes and expression of PD-1/ PD-L1 in high grade serous ovarian cancer. Oncotarget. 2016;7(12): 13587-98.

42. Howitt BE, Shukla SA, Sholl LM, Ritterhouse LL, Watkins JC, Rodig S, Stover E, Strickland KC, D'Andrea AD, Wu CJ, et al. Association of Polymerase emutated and microsatellite-instable endometrial cancers with Neoantigen load, number of tumor-infiltrating lymphocytes, and expression of PD-1 and PD-L1. JAMA Oncol. 2015;1(9):1319-23.

43. Perez-Trujillo JJ, Garza-Morales R, Barron-Cantu JA, Figueroa-Parra G, GarciaGarcia A, Rodriguez-Rocha H, Garcia-Juarez J, Munoz-Maldonado GE, Saucedo-Cardenas O, Montes-De-Oca-Luna R, et al. DNA vaccine encoding human papillomavirus antigens flanked by a signal peptide and a KDEL sequence induces a potent therapeutic antitumor effect. Oncol Lett. 2017; 13(3):1569-74.

44. Gomez-Gutierrez JG, Elpek KG, Montes de Oca-Luna R, Shirwan H, Sam Zhou H, McMasters KM. Vaccination with an adenoviral vector expressing calreticulin-human papillomavirus 16 E7 fusion protein eradicates E7 expressing established tumors in mice. Cancer Immunol Immunother. 2007; 56(7):997-1007.

45. Li H, Shao S, Cai J, Burner D, Lu L, Chen Q, Minev B, Ma W. Artificial human antigen presenting cells are superior to dendritic cells at inducing cytotoxic T cell responses. Immunology. 2017;152(3):462-71.

46. Ma W, Chen M, Kaushal S, McElroy M, Zhang Y, Ozkan C, Bouvet M, Kruse C, Grotjahn D, Ichim T, et al. PLGA nanoparticle-mediated delivery of tumor antigenic peptides elicits effective immune responses. Int J Nanomedicine. 2012;7:1475-87. 
47. Song C, Noh YW, Lim YT. Polymer nanoparticles for cross-presentation of exogenous antigens and enhanced cytotoxic T-lymphocyte immune response. Int J Nanomedicine. 2016;11:3753-64.

48. Petrizzo A, Conte C, Tagliamonte M, Napolitano M, Bifulco K, Carriero V, De Stradis A, Tornesello ML, Buonaguro FM, Quaglia F, et al. Functional characterization of biodegradable nanoparticles as antigen delivery system. J Exp Clin Cancer Res. 2015;34:114.

49. Wang B, Zaidi N, He LZ, Zhang L, Kuroiwa JM, Keler T, Steinman RM. Targeting of the non-mutated tumor antigen HER2/neu to mature dendritic cells induces an integrated immune response that protects against breast cancer in mice. Breast Cancer Res. 2012;14(2):R39.

50. Qendro V, Lundgren DH, Palczewski S, Hegde P, Stevenson C, Perpetua L, Latifi A, Merriman J, Bugos G, Han DK. Discovery of breast putative cancer antigens using an integrative platform of genomics-driven immunoproteomics. Proteomics. 2017:17:1600318.

51. Ott PA, Hu Z, Keskin DB, Shukla SA, Sun J, Bozym DJ, Zhang W, Luoma A, Giobbie-Hurder A, Peter $L$, et al. An immunogenic personal neoantigen vaccine for patients with melanoma. Nature. 2017;547(7662): 217-21.

52. Sahin U, Derhovanessian E, Miller M, Kloke BP, Simon P, Lower M, Bukur V, Tadmor AD, Luxemburger U, Schrors B, et al. Personalized RNA mutanome vaccines mobilize poly-specific therapeutic immunity against cancer. Nature. 2017;547(7662):222-6.

53. Loi S, Sirtaine N, Piette F, Salgado R, Viale G, Van Eenoo F, Rouas G, Francis $P$, Crown JP, Hitre E, et al. Prognostic and predictive value of tumorinfiltrating lymphocytes in a phase III randomized adjuvant breast cancer trial in node-positive breast cancer comparing the addition of docetaxel to doxorubicin with doxorubicin-based chemotherapy: BIG 02-98. J Clin Oncol. 2013;31(7):860-7.

54. Loi S, Michiels S, Salgado R, Sirtaine N, Jose V, Fumagalli D, KellokumpuLehtinen PL, Bono P, Kataja V, Desmedt C, et al. Tumor infiltrating lymphocytes are prognostic in triple negative breast cancer and predictive for trastuzumab benefit in early breast cancer: results from the FinHER trial. Ann Oncol. 2014;25(8):1544-50.

55. Adams S, Gray RJ, Demaria S, Goldstein L, Perez EA, Shulman LN, Martino S, Wang $\mathrm{M}$, Jones VE, Saphner TJ, et al. Prognostic value of tumor-infiltrating lymphocytes in triple-negative breast cancers from two phase III randomized adjuvant breast cancer trials: ECOG 2197 and ECOG 1199. J Clin Oncol. 2014;32(27):2959-66.

56. Pruneri G, Gray KP, Vingiani A, Viale G, Curigliano G, Criscitiello C, Lang I, Ruhstaller T, Gianni L, Goldhirsch A, et al. Tumor-infiltrating lymphocytes (TILs) are a powerful prognostic marker in patients with triple-negative breast cancer enrolled in the IBCSG phase III randomized clinical trial 22-00. Breast Cancer Res Treat. 2016;158(2):323-31.

57. Perez EA, Ballman KV, Tenner KS, Thompson EA, Badve SS, Bailey H, Baehner FL. Association of Stromal Tumor-Infiltrating Lymphocytes with RecurrenceFree Survival in the N9831 adjuvant trial in patients with early-stage HER2positive breast Cancer. JAMA Oncol. 2016;2(1):56-64

58. Tomioka N, Azuma M, Ikarashi M, Yamamoto M, Sato M, Watanabe Kl, Yamashiro K, Takahashi M. The therapeutic candidate for immune checkpoint inhibitors elucidated by the status of tumor-infiltrating lymphocytes (TILs) and programmed death ligand 1 (PD-L1) expression in triple negative breast cancer (TNBC). Breast Cancer. 2017;25(1):34-42.

59. Ishizuka JJ, Manguso RT, Cheruiyot CK, Bi K, Panda A, Iracheta-Vellve A, Miller $\mathrm{BC}$, Du PP, Yates KB, Dubrot J, et al. Loss of ADAR1 in tumours overcomes resistance to immune checkpoint blockade. Nature. 2019;565(7737):43-8.

\section{Ready to submit your research? Choose BMC and benefit from}

- fast, convenient online submission

- thorough peer review by experienced researchers in your field

- rapid publication on acceptance

- support for research data, including large and complex data types

- gold Open Access which fosters wider collaboration and increased citations

- maximum visibility for your research: over $100 \mathrm{M}$ website views per year

At BMC, research is always in progress.

Learn more biomedcentral.com/submissions 